\title{
Novel Ethyne-Linked Compounds Containing 1,8-Naphthalimide Group for Light Conversion Film
}

\author{
Hyun-Young Lee, Kyung-Won Kim², Chae-Eun Park, Geun-Hyeong Kim ${ }^{1}$ and Jae- \\ Hong Choi ${ }^{\text {la }}$ \\ ${ }^{1}$ Department of Textile System Engineering, Kyungpook National University, Daegu 702-701, Korea. \\ ${ }^{2}$ Department of Functional Material Engineering, Kyungpook National University, Daegu 702-701, \\ Korea. \\ a jaehong@knu.ac.kr ${ }^{1}$
}

\begin{abstract}
In order to regulate plant growth, we studied blue fluorescent for agriculture light conversion films. The light conversion film containing blue fluorescent can convert ultraviolet (UV) and violet light $(300-400 \mathrm{~nm})$ into the blue-green light $(400-500 \mathrm{~nm})$ which is the more active wavelength band in photosynthesis. A durable and weather-resistance is important properties for applicate agriculture light conversion films.1,8naphthalimide derivatives usually exhibit strong fluorescent emission on irradiation, excellent photoluminescence (PL) quantum efficiency, good photo-stability and film-forming properties as well as desirable chemical and thermal stabilities. In this study, 1,8-naphthalimide derivatives containing ethynyl link were synthesized and characterized. Synthesized fluorescent has high thermal stability and suitable photophysical properties for agriculture light conversion films.
\end{abstract}

\section{Introduction}

For photosynthesis light with the wavelengths from $400-700 \mathrm{~nm}$ is necessary. This part of the global radiation is called photosynthetically active radiation (PAR) [1]. Since the optimum light intensity and light are essential for optimum plant growth and development, much effort is focused on the development of transparent greenhouse covering material with improved optical properties [2]. In particular, light conversion films have been actively developed and are now gaining much attention. Light conversion film is a material that converts the less active wavelength band in photosynthesis to the more active wavelength of 400-700 nm. Plant growth under the light conversion film had not yet been sufficiently reviewed due to the difficulty in developing a durable and weather-resistant film [3]

1,8naphthalimide derivatives usually exhibit strong fluorescent emission on irradiation, excellentphotoluminescence (PL) quantum efficiency, good photo-stability and film-

\footnotetext{
* Corresponding author: jaehong@knu.ac.kr
} 
forming properties as well as desirable chemical and thermal stabilities. In this study, 1,8naphthalimide derivatives with ethynyllink was synthesized blue fluorescent and studied for apply light conversion film. The synth esized blue fluorescent was examined photophysical properties which is important to light c onversion and studied used of density functional theory (DET) calculations at the B3LYP/6$31 \mathrm{G}$ level of theory by Gaussian 09 suit of program.

\section{Synthesis}

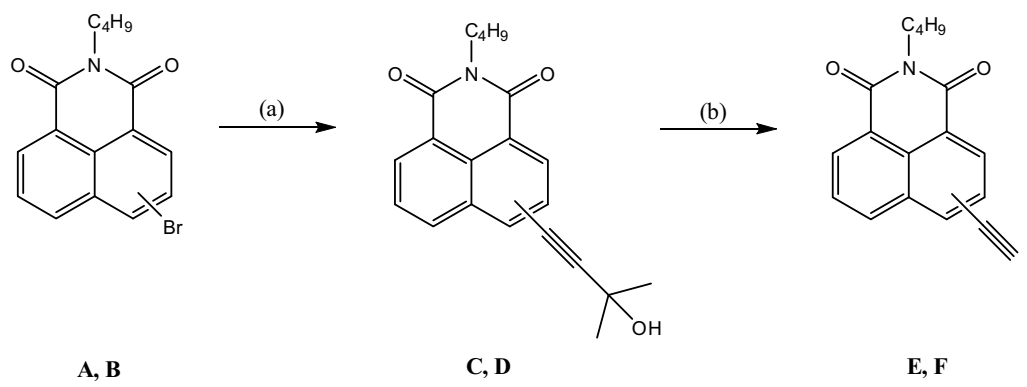

Scheme 1. Reagents and conditions: (a) 3-methyl-1-butyn-3-ol, $\mathrm{Pd}\left(\mathrm{PPh}_{3}\right)_{2} \mathrm{Cl}_{2}, \mathrm{CuI}$, TEA, under nitrogen, $80^{\circ} \mathrm{C}, 24 \mathrm{~h}$; (b) $\mathrm{KOH}$, toluene, under argon, reflux

Synthesis of Intermediate C-D. A mixture of the compounds A-B (1 mmol), 2-methylbut-3-yn-2-ol (3 mmol), cuprous iodide $(15.9 \mathrm{mg}, 0.05 \mathrm{mmol})$, triphenylphosphine $\left(\mathrm{PPh}_{3}\right.$; $13.1 \mathrm{mg}, 0.05 \mathrm{mmol})$, and tetrakis(triphenylphosphine)palladium $\left(\mathrm{Pd}\left(\mathrm{PPh}_{3}\right)_{4} ; 115 \mathrm{mg}, 0.1\right.$ mmol) was carefully degassed and charged with nitrogen. Anhydrous THF $(10 \mathrm{ml})$ and trimethylamine $(10 \mathrm{ml})$ were then added. The reaction was refluxed for $24 \mathrm{~h}$ under a nitrogen atmosphere. The reaction was terminated with ammonia water and extracted with $\mathrm{CH}_{2} \mathrm{Cl}_{2}$, washed with water, dried over anhydrous $\mathrm{MgSO}_{4}$, and evaporated to dryness. The crude product was purified by column chromatography on silica gel.

Intermediate C; Yields : 57.5\%, ${ }^{1} \mathrm{H}$ NMR (600MHZ, CDCl-d) $1.00\left(\mathrm{~m}, 3 \mathrm{H}, \mathrm{CH}_{3}\right), 1.26$ (t, $\left.2 \mathrm{H}, \mathrm{CH}_{2}\right), 1.47\left(\mathrm{~s}, 3 \mathrm{H}, \mathrm{CH}_{3}\right), 1.51\left(\mathrm{t}, 2 \mathrm{H}, \mathrm{CH}_{2}\right), 4.13\left(\mathrm{t}, 2 \mathrm{H}, \mathrm{CH}_{2}\right), 5.69(\mathrm{~s}, 1 \mathrm{H}, \mathrm{OH}), 7.90$ (s, $1 H, A r H), 8.49(\mathrm{~d}, 1 H, A r H), 8.58(\mathrm{~d}, 1 H, \mathrm{ArH}), 8.60(\mathrm{~d}, 1 H, \mathrm{ArH}), 8.71(\mathrm{~d}, 1 H, \mathrm{ArH})$, LC-MS $335(\mathrm{M}+)$

Intermediate D; Yields : $\quad 75.8 \%, \quad{ }^{1} \mathrm{H} \quad$ NMR $\quad(600 \mathrm{MHZ}, \quad \mathrm{CDCl}-$ d) $1.01\left(\mathrm{~m}, 3 \mathrm{H}, \mathrm{CH}_{3}\right), 1.26\left(\mathrm{t}, 2 \mathrm{H}, \mathrm{CH}_{2}\right), 1.48\left(\mathrm{~s}, 3 \mathrm{H}, \mathrm{CH}_{3}\right), 1.51\left(\mathrm{t}, 2 \mathrm{H}, \mathrm{CH}_{2}\right), 4.14(\mathrm{t}, 2 \mathrm{H}, \mathrm{C}$ $\left.\mathrm{H}_{2}\right), 5.69(\mathrm{~s}, 1 H, \mathrm{OH}), 7.89$ (s, $\left.1 H, \mathrm{ArH}\right), 7.90(\mathrm{~s}, 1 H, \mathrm{ArH}), 8.49$ (d, $\left.1 H, \mathrm{ArH}\right), 8.60(\mathrm{~d}, 1 H$, ArH), 8.71 (d, $1 H, \mathrm{ArH}), \mathrm{LC}-\mathrm{MS} 335(\mathrm{M}+)$

Synthesis of Intermediate E-F. To solution of the compound $(1 \mathrm{mmol})$ in anhydrous toluene $\mathrm{KOH}(168 \mathrm{mg}, 3 \mathrm{mmol})$ was added. The mixture was refluxed for $6 \mathrm{~h}$ under a nitrogen atmosphere. Then filtered, filtrate was evaporated to dryness. The crude product was purified by column chromatography on silica gel.

Intermediate E; Yields : 83.7\%, ${ }^{1} \mathrm{H}$ NMR (600MHZ, CDCl-d) 0.98 (m, 3H, $\left.\mathrm{CH}_{3}\right), 1.26$ (t, $\left.2 \mathrm{H}, \mathrm{CH}_{2}\right), 1.51\left(\mathrm{t}, 2 \mathrm{H}, \mathrm{CH}_{2}\right), 3.64\left(\mathrm{t}, 2 \mathrm{H}, \mathrm{CH}_{2}\right), 4.91(\mathrm{~s}, 1 \mathrm{H}, \mathrm{CH}), 7.90(\mathrm{~s}, 1 \mathrm{H}, \mathrm{ArH}), 8.49$ $(\mathrm{d}, 1 H, \mathrm{ArH}), 8.58(\mathrm{~d}, 1 H, \mathrm{ArH}), 8.60$ (d, $1 H, \mathrm{ArH}), 8.71(\mathrm{~d}, 1 H, \mathrm{ArH}) \mathrm{LC}-\mathrm{MS} 277(\mathrm{M}+)$

$\begin{array}{llllll}\text { Intermediate } & \mathbf{F} \text {; } \quad \text { Yields }: 85.7 \%, & { }^{1} \mathrm{H} & \mathrm{NMR} & (600 \mathrm{MHZ}, & \mathrm{CDCl}-\end{array}$ d) $1.00\left(\mathrm{~m}, 3 \mathrm{H}, \mathrm{CH}_{3}\right), 1.26\left(\mathrm{t}, 2 \mathrm{H}, \mathrm{CH}_{2}\right), 1.51\left(\mathrm{t}, 2 \mathrm{H}, \mathrm{CH}_{2}\right), 3.64\left(\mathrm{t}, 2 \mathrm{H}, \mathrm{CH}_{2}\right), 4.91(\mathrm{~s}, 1 \mathrm{H}, \mathrm{C}$ H), $7.89(\mathrm{~s}, 1 H, \mathrm{ArH}), 7.90(\mathrm{~s}, 1 H, \mathrm{ArH}), 8.49(\mathrm{~d}, 1 H, \mathrm{ArH}), 8.60(\mathrm{~d}, 1 H, \mathrm{ArH}), 8.71(\mathrm{~d}, 1 H$, ArH), LC-MS $277(\mathrm{M}+)$

Synthesis of Blue Fluorescent 1-3. A mixture of the compounds A-B (1.2 mmol), 
compounds E-F $(1.2 \mathrm{mmol})$, cuprous iodide $(15.9 \mathrm{mg}, 0.05 \mathrm{mmol})$, triphenylphosphine $\left(\mathrm{PPh}_{3} ; 13.1 \mathrm{mg}, 0.05 \mathrm{mmol}\right)$, and tetrakis(triphenylphosphine)palladium $\left(\mathrm{Pd}\left(\mathrm{PPh}_{3}\right)_{4} ; 115 \mathrm{mg}\right.$, $0.1 \mathrm{mmol})$ was carefully degassed and charged with nitrogen. Anhydrous THF $(15 \mathrm{ml})$ and trimethylamine $(15 \mathrm{ml})$ were then added. The reaction was refluxed for $24 \mathrm{~h}$ under a nitrogen atmosphere. The reaction was terminated with ammonia water and extracted with $\mathrm{CH}_{2} \mathrm{Cl}_{2}$, washed with water, dried over anhydrous $\mathrm{MgSO}_{4}$, and evaporated to dryness. The crude product was purified by column chromatography on silica gel.
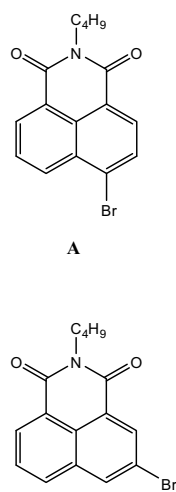

B
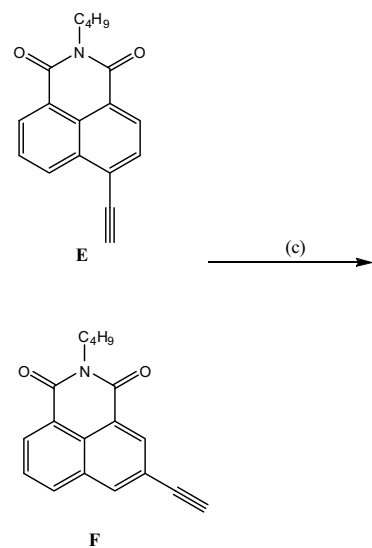
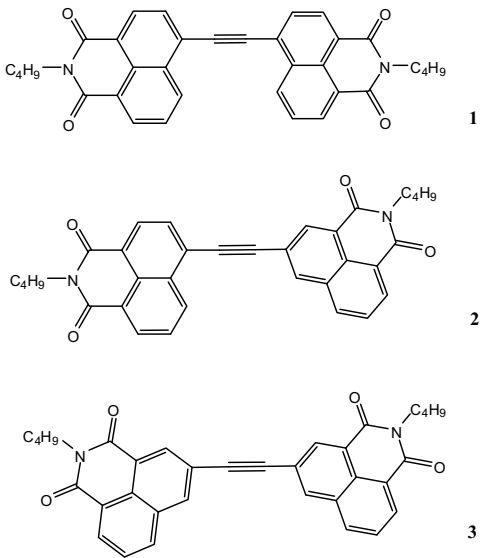

Scheme 2. Reagents and conditions: (c) $\mathrm{Pd}\left(\mathrm{PPh}_{3}\right)_{2} \mathrm{Cl}_{2}, \mathrm{CuI}, \mathrm{TEA}$, under nitrogen, $80{ }^{\circ} \mathrm{C}, 24 \mathrm{~h}$

Blue Fluorescent 1; Yields : 73.5\%, ${ }^{1} \mathrm{H}$ NMR (600MHZ, DMSO-d $\left.\mathrm{d}_{6}\right) 0.95\left(\mathrm{~m}, 6 \mathrm{H}, \mathrm{CH}_{3}\right)$, $1.32\left(\mathrm{t}, 4 \mathrm{H}, \mathrm{CH}_{2}\right), 1.51$ (t, $\left.4 \mathrm{H}, \mathrm{CH}_{2}\right), 3.64$ (t, $\left.4 H, \mathrm{CH}_{2}\right), 7.90$ (t, $\left.2 \mathrm{H}, \mathrm{ArH}\right), 8.49$ (t, $\left.2 \mathrm{H}, \mathrm{ArH}\right)$, 8.58 (d, 2H, ArH), 8.59 (d, 2H, ArH), 8.72 (d, 2H, ArH), LC-MS $528(\mathrm{M}+)$

Blue Fluorescent 2; Yields : 59.8\%, ${ }^{1} \mathrm{H}$ NMR (600MHZ, DMSO-d $\left.{ }_{6}\right) 0.94$ (m, 3H, $\left.\mathrm{CH}_{3}\right)$, $1.33\left(\mathrm{t}, 2 \mathrm{H}, \mathrm{CH}_{2}\right), 1.52\left(\mathrm{t}, 2 \mathrm{H}, \mathrm{CH}_{2}\right), 3.65\left(\mathrm{t}, 2 \mathrm{H}, \mathrm{CH}_{2}\right), 7.89$ (s, $\left.1 \mathrm{H}, \mathrm{ArH}\right), 7.90(\mathrm{~s}, 1 \mathrm{H}, \mathrm{ArH})$, $8.49(\mathrm{~d}, 1 H, \mathrm{ArH}), 8.60(\mathrm{~d}, 1 H, \mathrm{ArH}), 8.71(\mathrm{~d}, 1 H, \mathrm{ArH}), \mathrm{LC}-\mathrm{MS} 528(\mathrm{M}+)$

Blue Fluorescent 3; Yields : $51.3 \%,{ }^{1} \mathrm{H}$ NMR (600MHZ, DMSOd $\left.{ }_{6}\right) 0.94\left(\mathrm{~m}, 6 \mathrm{H}, \mathrm{CH}_{3}\right), 1.33\left(\mathrm{t}, 4 \mathrm{H}, \mathrm{CH}_{2}\right), 1.53\left(\mathrm{~s}, 4 \mathrm{H}, \mathrm{CH}_{2}\right), 3.67\left(\mathrm{t}, 2 \mathrm{H}, \mathrm{CH}_{2}\right), 5.69(\mathrm{~s}, 1 \mathrm{H}$, OH), 7.89 (s, 2H, ArH), $7.90(\mathrm{~s}, 2 H, \mathrm{ArH}), 8.49$ (d, $1 H, \mathrm{ArH}), 8.60(\mathrm{~d}, 1 H, \mathrm{ArH}), 8.71(\mathrm{~d}, 1$ $H, \mathrm{ArH}), \mathrm{LC}-\mathrm{MS} 528(\mathrm{M}+)$

Photophysical Property. We measured the photophysical property of 1-3 in $\mathrm{CH}_{2} \mathrm{Cl}_{2}$ $\left(2 \times 10^{-6} \mathrm{~mol} / \mathrm{L}\right)$ and the data summarized in Table 1 . Fluorescents exhibit a quite similar absorption curve and has molar extinction coefficient (Figure 1).

Absorption maxima of the Fluorescents were observed in the range of 328$338 \mathrm{~nm}$. It apparently indicated the effects of extension of $\pi$ conjugation, and absorption maxima of Fluorescent $\mathbf{3}$ is bathochromically shifted relative to of 2. These results confirm that the connection at same position of 1,8naphthalimide is more effective for the extension of $\pi$-conjugation than that at the other Table 1. Photochemical Properties Of The Fluorescent (1 3)

\begin{tabular}{cccccc}
\hline $\begin{array}{c}\text { Fluorescent } \\
\text { number }\end{array}$ & $\lambda_{\max (\mathbf{n m})}$ & $\varepsilon_{\max }$ & $\lambda_{\mathrm{em}}(\mathrm{nm})$ & $\phi$ & $\begin{array}{c}\text { Stokes' shifts } \\
(\mathrm{nm})\end{array}$ \\
\hline 1 & 334 & 17,000 & 425 & 0.57 & 93 \\
2 & 338 & 15,000 & 432 & 0.48 & 94 \\
3 & 333 & 19,000 & 426 & 0.69 & 93 \\
\hline
\end{tabular}




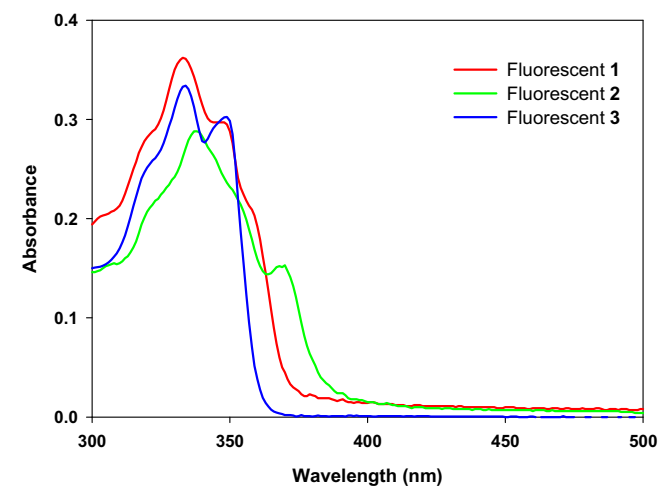

Figure 1. Absorption of Fluorescent (1 3) (Determined in $\mathrm{CH}^{2} \mathrm{Cl}^{2}$, the concentration of the compounds were $2 \times 10^{-6} \mathrm{~mol} / \mathrm{L}$ )

position when the two different 1,8-naphthalimide moieties are connected directly. The color of fluorescents ranges from blue to green. It is the case with the absorption maxima of fluorescents, their emission maxima are generally dependent on the conjugation connectivity of the two 1,8-naphthalimides moieties. Thus, emission maxima of the fluorescent increased in order of

Fluorescent $3<1<2$. Fluorescents have high quantum yields. The conjugation connectivity of 1,8- naphthalimide and ethynyl link also affect the quantum yields of 0.81 0.60 , respectively.

TD-DFT and frontier molecular orbital (FMO) calculation. An electronic excitation results in some electron density redistribution that affects the molecular geometry. The major assignments of the lowest electronic transitions for Fluorescent 1-3 are mainly as HOMO $\rightarrow$ LUMO, which corresponds to a $\pi \rightarrow \pi^{*}$ excited singlet state as visualized in Figure 3. For 1, The HOMO and LUMO are spread over the whole conjugated molecule. The HOMO and LUMO energy levels of dyes are summarized in Table 2. Although both HOMO and LUMO of Fluorescent $\mathbf{2}$ had lower energy levels than Fluorescent 3, the difference in the HOMOs between $\mathbf{1 b}$ and $\mathbf{3 b}$ (1.66) was more significant than that between their HOMOs (0.52). Therefore, the position of ethynyl link on the 1,8-naphthalimide affected the HOMO, resulting in the broad energy band gap. The optical band gaps of dyes from the absorption edges were 3.74-5.76. The trend of the band gap $(2>1>3)$ was consistent with the results from the DFT calculations. 


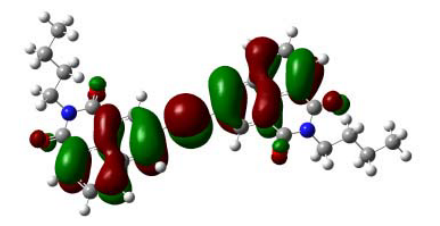

1

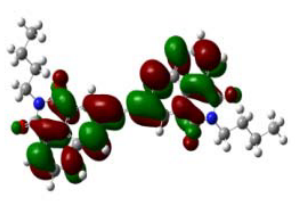

HOMO

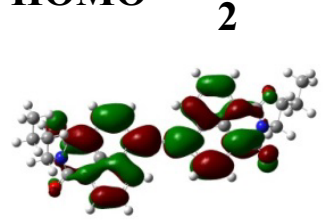

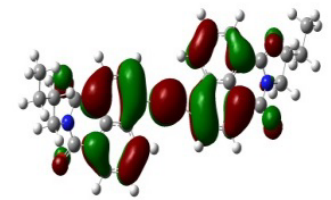

LUMO

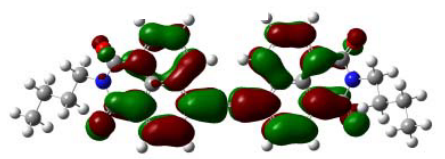

Figure 2. Molecular orbital plots of Fluorescent 1 3 (B3LYP/6-31G)

Table 2. homo-lumo energies and energy band gap of fluorescent 1 3 based on td-dft calculations.

\begin{tabular}{cccc}
\hline \multirow{2}{*}{$\begin{array}{c}\text { Fluorescent } \\
\text { number }\end{array}$} & \multicolumn{3}{c}{ Electochemical } \\
\cline { 2 - 4 } & HOMO $(\mathrm{eV})$ & LUMO $(\mathrm{eV})$ & Band gab $(\mathrm{eV})$ \\
\hline 1 & -5.84 & -0.96 & 4.88 \\
2 & -5.92 & -0.16 & 5.76 \\
3 & -4.18 & -0.44 & 3.74 \\
\hline
\end{tabular}

Thermal stability. To investigate the thermal stability of Fluorescent 1-3, thermogravimetric analysis (TGA) were performed, corresponding data shown table 3. All samples were heated at a rate $10^{\circ} \mathrm{Cmin}^{-10}$, under flowing nitrogen to $500^{\circ} \mathrm{C}$. To applicate agriculture film, fluorescent must be sufficient to survive the production process which is generally carried out $200^{\circ} \mathrm{C}$. The weight reduction of Fluorescent $\mathbf{1 - 3}$ is less than $2 \%$. The TGA revealed that Fluorescent $\mathbf{1 - 3}$ are highly stable materials, which decompose at temperatures higher than $259^{\circ} \mathrm{C}$. Therefore, the results indicated that these synthesized Fluorescent 1-3 were of high morphological and thermal stabilities, which is critical issue for film stability and life time.

Table 3. Thermogravimetric Analysis (Tga) Of Fluorescent 1 3

\begin{tabular}{ccc}
\hline Fluorescent number & $\begin{array}{c}\text { Weight of reduction }(\%, \\
\left.200^{\circ} \mathrm{C}\right)\end{array}$ & Decomposition Temp $\left({ }^{\circ} \mathrm{C}\right)$ \\
\hline 1 & 0.92 & 263 \\
2 & 1.51 & 259 \\
3 & 1.12 & 265 \\
\hline
\end{tabular}

\section{Summary}

Fluorescent, which is 1,8-naphthalimide derivatives containing ethynyl link, were prepared and evaluated in terms of the properties needed for the agriculture light conversion film. And Fluorescent 1, 3 effectively convert UV into blue light, thereby assume they activate photosynthesis. 
Fluorescents 1-3 were Absorption maxima of the Fluorescents were observed in the range of 328-338 $\mathrm{nm}$. It apparently indicated the effects of extension of $\pi$-conjugation. It also affected emission spectra and energy band gap. The position of ethynyl link on the 1,8naphthalimide affected the HOMO, resulting in the broad energy band gap. These results confirm that the connection at same position of 1,8-naphthalimide is more effective for the extension of $\pi$-conjugation than that at the other position when the two different 1,8 naphthalimide moieties are connected directly.

Fluorescents 1-3 have high thermal stability and excellent photophysical properties for forming agriculture light conversion film.

\section{References}

1. CIE 106/5, Collection in Photobiology and Photochemistery.Commission Internationale de l'eclairage (CIE), (1993) ISBN 3900734461, 29.

2. PEARSON, S., A.E. WHELDON and P. HADLEY 1995: Radiation transmission and fluorescence of nine greenhouse cladding materials. J. Agr. Eng. Res. 62 (1995) 61-70.

3. Nishimura Y., Y. Fukumoto, H. Aruga, and Y. Shimoi. Growth and developmental characteristics of vegetable grown under light conversion film. Hort. Environ. Biotechnol. 50 (2009) 416-421. 